\title{
Silagem de cereais de inverno submetidos ao manejo de duplo propósito ${ }^{1}$
}

\author{
Gilmar Roberto Meinerz², Clair Jorge Olivo ${ }^{3}$, Julio Viégas ${ }^{3}$, José Laerte Nörnberg ${ }^{4}$, Carlos \\ Alberto Agnolin ${ }^{2}$, Rudolf Brand Scheibler ${ }^{5}$, Tiago Horst ${ }^{5}$, Renato Serena Fontaneli ${ }^{6}$
}

\author{
1 Pesquisa financiada com recursos do Conselho Nacional de Desenvolvimento Científico e Tecnológico. \\ 2 Programa de Pós-graduação em Zootecnia, Universidade Federal de Santa Maria (UFSM), RS, Brasil, $97105-900$. \\ ${ }^{3}$ Departamento de Zootecnia, UFSM, RS, Brasil. \\ ${ }^{4}$ Departamento de Tecnologia e Ciência dos Alimentos, UFSM, RS, Brasil. \\ ${ }^{5}$ Acadêmicos do curso de Zootecnia - UFSM. \\ ${ }^{6}$ Centro Nacional de Pesquisa do Trigo (CNPT - EMBRAPA).
}

RESUMO - Esta pesquisa foi conduzida com o objetivo de avaliar a silagem de 12 genótipos de seis espécies de cereais de inverno de duplo propósito (forragem e grãos), submetidos ao corte na região da Depressão Central do Rio Grande do Sul. As espécies e os genótipos testados foram: trigo BRS 277, BRS Guatambu, BRS Tarumã, BRS Umbu; aveia-preta Agro zebu, UPFA 21 Moreninha e Comum; aveia-branca UPF 18; centeio BR 1 e BRS Serrano; Cevada BRS Marciana; e triticale BRS 148. Os genótipos foram submetidos a três cortes com o objetivo de simular o pastejo, conforme manejo indicado para duplo propósito. Após o terceiro corte, permitiu-se o desenvolvimento das culturas para a ensilagem. As silagens foram feitas em silos experimentais de PVC quando as forrageiras atingiram o estádio fenológico de grão pastoso. O delineamento experimental foi o inteiramente casualizado, com 12 tratamentos (genótipos) e três repetições (parcelas). Foram determinadas a produção de matéria seca e a composição estrutural do material ensilado, o valor nutritivo e os parâmetros fermentativos das silagens. O centeio BR 1 e a aveiabranca UPF 18 apresentaram as maiores produções de matéria seca. O trigo BRS Umbu produziu silagem com maior participação de grãos e valor nutritivo mais elevado. Todos os genótipos apresentaram condições satisfatórias para a ensilagem.

Palavras-chave: capacidade tampão, forragem conservada, integração lavoura-pecuária, proteína bruta

\section{Silage of winter cereals submitted to double purpose management}

ABSTRACT - The objective of this research was to evaluate the silage of 12 genotypes of six species of double purpose winter cereals (forage and grains) submitted to harvest at Depressão Central region of Rio Grande do Sul state. Species and genotypes tested were: BRS 277, BRS Guatambu, BRS Tarumã and BRS Umbu wheat; Agro Zebu, UPFA 21 - Moreninha and Commom black-oat; UPF 18 white oat; BR 1 and BRS Serrano rye; BRS Marciana barley; and BRS 148 triticale. Genotypes were submitted to tree harvests with the objective to simulate grazing, according to double purpose management. After the third harvest, the development of cultures was permitted for silage production. The genotypes were distributed in 36 experimental plots in a completely randomized experimental design with 12 treatments (genotypes) and three replications (plots). Silages were made in PVC experimental silos when forages achieved phenological stage of soft dough. Fermentative parameters, dry matter production, structural and botanical composition of ensilage material and nutritive value of silages were determined. BR 1 rye and UPF 18 white oat presented the highest dry matter yield. BRS Umbu wheat produced silage with higher grain participation and better nutritive value. All genotypes presented satisfactory conditions for ensilage.

Key Words: buffering capacity, conserved forage, crude protein, livestock-crop production system

\section{Introdução}

O Sul do Brasil possui condições edafoclimáticas favoráveis ao cultivo de muitas espécies de plantas forrageiras. No entanto, a estacionalidade na produção de forragem da maioria das espécies utilizadas ocasiona um vazio forrageiro no outono e início do inverno, quando as espécies de verão já completaram seu ciclo e as de inverno ainda não estão prontas para a utilização (SchefferBasso et al., 2004).

Neste sentido, a utilização de forragens conservadas na alimentação de vacas leiteiras é uma prática bastante usual nos períodos de carência de forragem e visa fornecer alimento volumoso de boa qualidade e em quantidades suficientes para a manutenção dos níveis de produtividade. Dentre as formas de conservação da forragem destaca-se a 
ensilagem, que consiste no corte da planta forrageira em momento ideal e posterior armazenamento da massa verde picada em silos (Novaes et al., 2004). Este processo tem como principal objetivo conservar a forragem e, desde que seja realizado em condições ideais, manter a qualidade do material original (Van Soest, 1994).

As principais culturas usadas para produção de silagem são o milho e o sorgo, culturas típicas de verão. Entretanto, há necessidade de se estudar a utilização de novas culturas na confecção da silagem, no sentido de reduzir os custos de produção (Pinto et al., 2007). Com a expansão dos sistemas de produção baseados na integração lavoura-pecuária, a utilização de cereais de inverno de duplo propósito (forragem e grãos) surge como uma alternativa para produção de silagem de qualidade, com baixo custo, considerando-se que no final do ciclo dessas culturas, normalmente há um excedente de massa de forragem.

A silagem de cereais de inverno apresenta, geralmente, maiores teores de proteína bruta do que a silagem de milho, mas com valor energético inferior (Scheffer-Basso et al., 2003). As principais espécies utilizadas para ensilagem são aveia-preta e azevém, colhidos no estádio de elongamento e submetidos ao pré-murchamento antes da ensilagem, tendo em vista que o excesso de umidade é prejudicial ao processo de fermetação e conservação do material ensilado. O estádio fenológico indicado para ensilagem de cereais de inverno sem pre-murchamento é o de grão pastoso (Fontaneli et al., 2009). Há, no entanto, carência de informações sobre diversos fatores envolvidos na ensilagem destes materiais. Assim, o objetivo neste trabalho foi avaliar silagens de cereais de inverno submetidos ao manejo de duplo propósito na Depressão Central de Rio Grande do Sul.

\section{Material e Métodos}

A pesquisa foi conduzida no Laboratório de Bovinocultura de Leite do Departamento de Zootecnia da UFSM, localizado na região fisiográfica denominada Depressão Central do Rio Grande do Sul, com altitude de $95 \mathrm{~m}$, latitude $29^{\circ} 43^{\prime}$ Sul e longitude $53^{\circ} 42^{\prime}$ Oeste, no período entre março e outubro de 2008. As médias de temperatura e a precipitação pluviométrica do período foram de $14,86^{\circ} \mathrm{C}$ e 985,2 mm (168,89 mm mensais). Esses valores são similares às médias climáticas normais da região. O solo da área experimental é classificado como Argissolo Vermelho distrófico arênico, pertencente à unidade de mapeamento São Pedro (Embrapa, 1999) e o clima da região é o Cfa (subtropical úmido), conforme classificação de Köppen (Moreno, 1961).
Foram testados 12 genótipos de seis espécies de cereais de inverno de duplo propósito de utilização: trigo (BRS 277, BRS Guatambu, BRS Tarumã, BRS Umbu); aveia-preta (Agro Zebu, UPFA 21 - Moreninha e Comum); aveia-branca (UPF 18); centeio (BR 1 e BRS Serrano); cevada (BRS Marciana); e triticale (BRS 148).

A área experimental foi dividida em 36 parcelas experimentais, com dimensões de $5 \mathrm{~m}$ de comprimento e $3 \mathrm{~m}$ de largura. Os dados da análise do solo foram os seguintes: índice SMP 5,2; P 2,2 mg/dm; K 0,12 $\mathrm{cmol}_{\mathrm{c}} / \mathrm{dm}^{3} ; \mathrm{Al}^{3+}$ $2,7 \mathrm{cmol}_{\mathrm{C}} / \mathrm{dm}^{3} ; \mathrm{Ca}^{2+} 3,1 \mathrm{cmol}_{\mathrm{C}} / \mathrm{dm}^{3} ; \mathrm{Mg}^{+}{ }^{2}, 5 \mathrm{cmol}_{\mathrm{C}} / \mathrm{dm}^{3}$; MO 2,3\%; saturação de bases 30,0\% e saturação por alumínio $36 \%$. A semeadura foi feita em 10 de abril, em linhas com espaçamento de $17 \mathrm{~cm}$ e com sementes provenientes do Centro Nacional de Pesquisa do Trigo (CNPT-EMBRAPA), em Passo Fundo, Rio Grande do Sul. A densidade de semeadura foi de 400 sementes viáveis $/ \mathrm{m}^{2}$. Trinta dias antes da semeadura, foi realizada a correção da acidez, conforme a análise do solo, mediante a aplicação de calcário dolomítico do tipo Filler, incorporado mediante escarificação do solo. A adubação potássica e fosfórica foi realizada conforme as recomendações da Comissão de Química e Fertilidade do Solo - RS/SC (2004), individualmente para cada espécie. A adubação nitrogenada, foi de $120 \mathrm{~kg} / \mathrm{ha}$ de $\mathrm{N}$ para todas as espécies, sendo aplicado $10 \mathrm{~kg} / \mathrm{ha}$ na semeadura e $110 \mathrm{~kg} / \mathrm{ha}$ em cobertura, divididos em 4 aplicações.

As forrageiras foram submetidas ao manejo de cortes indicado para duplo propósito. Foram realizados três cortes com o objetivo de simular o pastejo, em intervalos variando entre 16 e 38 dias. Após o terceiro corte, foi realizado o diferimento, permitindo-se o desenvolvimento final das culturas. No estádio fenológico de grão pastoso, metade da área de cada parcela foi destinada à confecção das silagens e a outra metade foi utilizada para avaliação do rendimento de grãos. Para fins de amostragem e coleta de material para ensilagem foram desconsiderados $15 \mathrm{~cm}$ de cada um dos lados das parcelas (bordaduras).

O rendimento de forragem foi estimado através de cinco amostras por parcela, cortadas rente ao solo, sendo utilizado um quadro com dimensões de $50 \times 30 \mathrm{~cm}$. As amostras foram homogeneizadas, sendo retirada uma subamostra para estimativa das composições botânica e estrutural da forragem, fazendo-se manualmente a separação da lâmina foliar, colmo+bainha, material senescente, espigueta/panículas, grãos e outras espécies. Estes componentes foram secos em estufa de ar forçado a $55^{\circ} \mathrm{C}$ até peso constante para determinação dos teores de matéria parcialmente seca. 
A confecção das silagens foi realizada entre 20 de setembro e 24 de outubro. A forragem foi cortada rente ao solo, sendo triturada em moinho forrageiro regulado para fragmentar o material em partículas de $1,5 \mathrm{~cm}$. O material foi compactado e hermeticamente fechado em silos experimentais de PVC com 100 mm de diâmetro e $50 \mathrm{~cm}$ de altura, com tampas com válvulas de Bunsen para permitir o escape dos gases, e acondicionados em sala protegida da radiação solar.

A abertura dos silos foi realizada após 40 dias de fermentação, desprezando-se a porção superior de cada um. O restante do material foi homogeneizado, retirando-se uma subamostra para a determinação do $\mathrm{pH}$ em potenciômetro digital (Silva \& Queiroz, 2002) e da capacidade tampão (Playne \& McDonald, 1966). Com auxílio de uma prensa, foi retirado suco para a determinação do nitrogênio amoniacal (N-NH3) por destilação com óxido de magnésio (Chaney \& Marbach, 1962). O restante da amostra foi parcialmente seca em estufa de ventilação forçada, a $55{ }^{\circ} \mathrm{C}$ até peso constante, sendo posteriormente moída em moinho do tipo Willey em peneira com malha de $1 \mathrm{~mm}$ e acondicionada para a realização das análises laboratoriais.

As determinações de matéria seca(MS), matéria orgânica (MO), fibra em detergente ácido corrigida para cinzas (FDAc), lignina em detergente ácido (ácido sulfúrico), proteína bruta (PB), nitrogênio insolúvel em detergente neutro (NIDN) e nitrogênio insolúvel em detergente ácido (NIDA) foram realizadas segundo procedimentos descritos por Silva \& Queiroz (2002). Para determinação da fibra em detergente neutro corrigida para cinzas (FDNc) não foi utilizado sulfito de sódio na solução em detergente neutro, sendo empregada $\alpha$-amilase termoestável. Por isso, a proteína remanescente na FDNc foi subtraída após a multiplicação do fator 6,25 pelo teor do NIDN. A abreviação FDNcp expressa o teor de fibra em detergente neutro determinada com o uso de $\alpha$-amilase termoestável, descontando-se a proteína insolúvel em detergente neutro e as cinzas residuais. Também foi determinada a fibra em detergente ácido corrigida para cinzas (FDAc) e para proteína (FDAcp).

O delineamento experimental utilizado foi o inteiramente casualizado, com 12 tratamentos (genótipos), três repetições (parcelas). Os resultados foram submetidos à análise de variância e as médias comparadas entre si pelo teste Tukey a 5\% de probabilidade do erro. Os dados foram submetidos à análise de correlação, pelo coeficiente de Pearson.

\section{Resultados e Discussão}

Os genótipos testados apresentaram ciclos distintos, sendo o triticale BRS 148 e o centeio BR 1 os mais precoces para produção de silagem, com 150 dias entre a emergência e o estádio de grão pastoso (Tabela 1). Os genótipos mais tardios foram os trigos BRS 277, BRS Guatambu, BRS Tarumã, o centeio BRS Serrano e as aveias UPF 18 e UPFA 21 - Moreninha, que apresentaram ciclo superior a 180 dias. A estatura das plantas no momento da ensilagem foi distinta entre os genótipos, sendo que o genótipo que apresentou maior altura foi o centeio BRS Serrano e o trigo BRS Tarumã a menor. Não foi observado acamamento nos materiais estudados.

Para os teores de matéria seca das silagens (Tabela 1), foram verificados resultados distintos entre os genótipos, que variaram de 24 a $42 \%$ de MS. Os valores mais elevados foram observados para os trigos BRS 277 e BRS Guatambu, que apresentaram teores de matéria seca superiores à $40 \%$. No entanto, não foi constatada presença de mofo ou desenvolvimento de fungos. O teor de MS afeta a qualidade fermentativa da silagem, que está relacionada tanto ao potencial de ingestão quanto à eficiência de utilização de nutrientes para produção animal (McDonald, 1981). À

Tabela 1 - Rendimento de matéria seca (MS) e características da forragem pré-ensilada de cereais de inverno submetidos ao manejo de duplo propósito

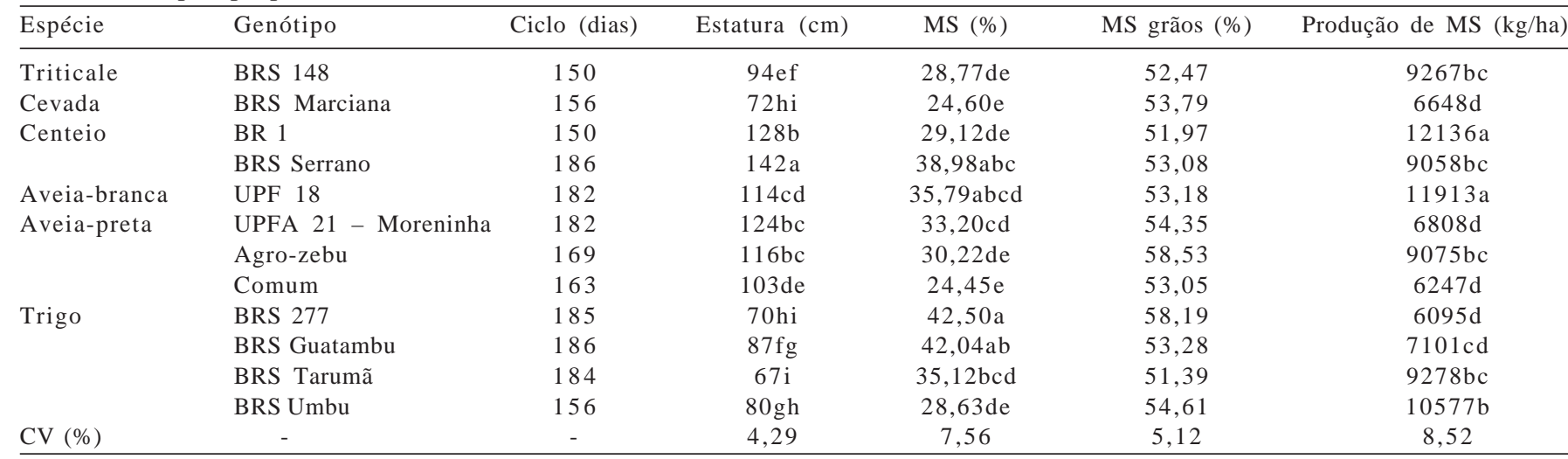

Médias seguidas por letras distintas na coluna diferem entre si pelo teste de Tukey a 5\% de probabilidade. 
exceção da aveia-preta Comum e da cevada BRS Marciana, os teores de MS ficaram próximos aos preconizados por Noller et al. (1954) para que ocorram as menores perdas durante o processo fermentativo.

Apesar da grande variabilidade entre os teores de matéria seca das silagens, o teor de matéria seca dos grãos foi similar entre os genótipos testados: em média de 54\%. Este resultado indica que não houve diferença no estádio fenológico de desenvolvimento entre os genótipos no momento da ensilagem.

Com relação à produção de matéria seca (Tabela 1), os maiores rendimentos foram obtidos com o centeio BR 1 e a aveia-branca UPF 18, com valores próximos a 12 t/ha de MS. Estes resultados são superiores aos relatados por Primavesi et al. (2001) em estudo no qual avaliaram diferentes cultivares de aveia-branca. Floss et al. (2003), também com aveiabranca, obtiveram 11,4 t/ha de MS, no estádio de grão em massa dura. Os menores rendimentos, inferiores a $7 \mathrm{t} / \mathrm{ha}$ de MS foram obtidos com o trigo BRS 277, a aveia-preta Comum, UPFA 21-Moreninha e a cevada BRS Marciana, que, por sua vez, não diferiram entre si.

Para a composição estrutural do material pré-ensilado (Tabela 2) foram observadas diferenças significativas entre os genótipos. As menores participações de grãos foram obtidas nos genótipos de aveia-preta e no centeio BR1. Os trigos BRS Umbu, BRS Tarumã, BRS 277 e a aveia UPF 18 apresentaram maiores participações de grãos na massa ensilada. Segundo Mayombo et al. (1997), a maior proporção de grãos na forragem confere uma melhor qualidade à silagem. No entanto, a qualidade da fração fibrosa do caule, folhas, espiga e palhas, combinada com o percentual de cada uma dessas partes na planta, também determina o valor nutritivo do material ensilado (Barrière et al., 1997). As silagens foram compostas principalmente por colmos e grãos, com pequenas contribuições de lâminas foliares e material morto. A participação de lâminas foliares foi maior para o trigo BRS Umbu e para a cevada BRS Marciana.

No momento da abertura dos silos, não foi observado odor de amônia ou mesmo de forragem apodrecida, indicando que o processo de fermentação ocorreu de maneira satisfatória. Os valores de $\mathrm{pH}$ das silagens (Tabela 3) foram diferentes entre os genótipos e mantiveram-se dentro do preconizado para que ocorra fermentação adequada, com valores de pH entre 3,7 e 4,2 (Kung Júnior \& Stokes, 2003), exceto o centeio BR 1, que apresentou pH de 4,39.

A estabilização do $\mathrm{pH}$ na silagem deve-se às interações entre a concentração da matéria seca, da capacidade tamponante (Fisher \& Burns, 1987), das concentrações de carboidratos solúveis, do teor de lactato e das condições de anaerobiose do meio (Moisio \& Heikonen, 1994). A correlação negativa encontrada entre o pH e o teor de matéria seca ( $\mathrm{r}=-0,35 ; \mathrm{P}=0,03)$, embora baixa, indica a associação existente entre estas duas variáveis.

A capacidade tamponante das silagens (Tabela 3), que consiste na capacidade do material em resistir às alterações de $\mathrm{pH}$, foi diferente entre os genótipos e teve estreita correlação com os teores de matéria seca $(r=0,91 ; \mathrm{P}<0,0001)$. Os maiores valores de capacidade tampão foram observados para a aveia-preta Comum e para a cevada BRS Marciana, indicando que estes materiais apresentam maior resistência à elevação do pH. Este parâmetro é de fundamental importância para a conservação da qualidade da silagem após a abertura do silo, uma vez que com a rápida elevação do pH e a exposição ao ar, propiciam-se condições para que certos microrganismos indesejáveis tornem-se metabolicamente ativos, produzindo calor e consumindo nutrientes da silagem (Ranjit \& Kung Júnior, 2000).

O teor de nitrogênio amoniacal foi diferente entre os genótipos, mas manteve-se abaixo do limite máximo de $10 \%$ do nitrogênio total, preconizado por Ferreira (2001) para

Tabela 2 - Composição botânica e estrutural (\% da massa seca total) da forragem pré-ensilada de cereais de inverno submetidos ao manejo de duplo propósito

\begin{tabular}{|c|c|c|c|c|c|c|c|}
\hline Espécie & Genótipo & Lâminas foliares & Colmo + bainha & Material morto & Espiga/panícula & Grãos & Outras espécies \\
\hline Triticale & BRS 148 & $3,80 \mathrm{bc}$ & 41,91ab & $4,69 c$ & $15,68 a b$ & 24,24bcd & $9,66 \mathrm{ab}$ \\
\hline Cevada & BRS Marciana & $6,14 \mathrm{ab}$ & 40,36ab & $12,83 a b c$ & $4,06 \mathrm{~d}$ & $17,10 \mathrm{ef}$ & $19,49 a$ \\
\hline \multirow[t]{2}{*}{ Centeio } & BR 1 & 3,99abc & $49,58 a$ & 9,78abc & 8,50bcd & $15,67 \mathrm{fg}$ & $12,45 a b$ \\
\hline & BRS Serrano & $2,74 \mathrm{c}$ & 41,44ab & 13,8ab & 11,84abcd & 20,06def & 10,09ab \\
\hline Aveia-branca & UPF 18 & $3,16 \mathrm{bc}$ & 42,05ab & $15,58 a$ & $5,65 \mathrm{~cd}$ & 25,68abcd & $7,86 \mathrm{ab}$ \\
\hline \multirow[t]{3}{*}{ Aveia-preta } & UPFA 21 - Moreninha & 3,09bc & $44,43 a$ & $13,88 a b$ & $4,74 d$ & $16,17 \mathrm{fg}$ & $17,67 \mathrm{ab}$ \\
\hline & Agro-zebu & 3,63bc & $45,17 a$ & 9,31abc & 9,96abcd & $14,10 f g$ & $17,82 \mathrm{ab}$ \\
\hline & Comum & $2,84 \mathrm{c}$ & $48,09 a$ & 8,79abc & 12,09abcd & $9,88 \mathrm{~g}$ & $18,29 a$ \\
\hline \multirow[t]{4}{*}{ Trigo } & BRS 277 & $3,26 b c$ & $27,00 b$ & 9,76abc & 12,18abcd & $29,46 a b c$ & $18,32 \mathrm{a}$ \\
\hline & BRS Guatambu & $2,55 c$ & $35,66 a b$ & $9,80 \mathrm{abc}$ & $17,63 a$ & 23,01cde & $11,32 \mathrm{ab}$ \\
\hline & BRS Tarumã & $3,6 \mathrm{bc}$ & $27,31 b$ & $6,46 \mathrm{bc}$ & 13,84abc & 30,89ab & $17,85 a b$ \\
\hline & BRS Umbu & $7,06 a$ & 42,76ab & $5,14 \mathrm{bc}$ & 9,00abcd & $31,17 \mathrm{a}$ & $4,86 b$ \\
\hline CV (\%) & - & 27,2 & 13,62 & 30,81 & 29,25 & 10,63 & 32,77 \\
\hline
\end{tabular}

Médias seguidas por letras distintas na coluna diferem entre si pelo teste Tukey a 5\% de probabilidade. 
silagens de boa qualidade. Os teores observados no presente trabalho indicam que houve pequena degradação da proteína no processo de ensilagem. Isto se deve, provavelmente, ao fato de que a atividade proteolítica diminui com o aumento do teor de MS do material ensilado e com o rápido abaixamento do pH (Pereira \& Reis, 2001).

Para a porcentagem de PB (Tabela 4) foram observadas diferenças entre os genótipos. Os maiores valores foram observados para o triticale BRS 148 e os menores para a aveia-preta UPFA 21- Moreninha, sendo que os demais genótipos apresentaram teores intermediários. Os valores observados foram inferiores aos relatados por Coan et al. (2001), que, trabalhando com cultivares de aveia-preta e triticale ensilados no estádio de grão pastoso a farináceo, obtiveram teores médios de 10,85 e $10,45 \%$ de PB, respectivamente.

Os resultados deste trabalho são semelhantes aos relatados por Dumont et al. (1989), que observaram valores de 7,3\% de PB para a aveia-branca, colhida no estádio de grão pastoso. Excetuando-se o trigo BRS 277, a aveia-branca UPF
18, as aveias-pretas UPFA 21-Moreninha, Agro-zebu e o centeio BRS Serrano, os teores de PB observados situaram-se acima do limite mínimo de 7\%, considerado por Van Soest (1994), para que não ocorram limitações ao crescimento microbiano, permitindo adequada fermentação ruminal.

Considerando os valores de NIDA e NIDN, não foram observadas diferenças entre os genótipos, sendo os teores de NIDA das silagens bastante elevados. Van Soest (1994) sugere que variações de 3 a 15\% desta fração na MS estariam dentro da normalidade. Geralmente, os teores mais elevados de NIDA estão associados à formação de compostos de Mailard, em decorrência da elevação da temperatura nos silos (Evangelista et al., 2004). Os teores de NIDN observados são inferiores aos relatados por Oliveira (2008), que verificou valor médio de $20,3 \%$ para silagens de milho, sorgo sudão, sorgo forrageiro e girassol. O NIDN corresponde à fração do nitrogênio que se disponibiliza lentamente em ambiente ruminal.

Os teores de FDNc e FDNcp (Tabela 5) apresentaram as mesmas diferenças entre os genótipos estudados, sendo

Tabela 3 - Parâmetros fermentativos da silagem de cereais de inverno submetidos ao manejo de duplo propósito

\begin{tabular}{|c|c|c|c|c|}
\hline Espécie & Genótipo & $\mathrm{pH}$ & Capacidade tampão (eq.mg NaOH/100g MS) & $\mathrm{N}-\mathrm{NH}_{3} *$ \\
\hline Triticale & BRS 148 & 4,13ab & $18,80 \mathrm{abc}$ & $5,80 \mathrm{bcd}$ \\
\hline Cevada & BRS Marciana & $3,92 \mathrm{bcd}$ & $22,92 \mathrm{a}$ & 4,78abcd \\
\hline \multirow[t]{2}{*}{ Centeio } & BR 1 & $4,39 a$ & $17,56 a b c$ & 5,92abc \\
\hline & BRS Serrano & $3,78 \mathrm{~cd}$ & $14,87 \mathrm{bc}$ & $5,72 \mathrm{abc}$ \\
\hline Aveia-branca & UPF 18 & $3,78 \mathrm{~cd}$ & $14,72 \mathrm{bc}$ & $3,21 d$ \\
\hline \multirow[t]{3}{*}{ Aveia-preta } & UPFA 21 - Moreninha & 3,98cd & $16,81 \mathrm{bc}$ & 4,67bcd \\
\hline & Agro-zebu & $4,11 \mathrm{ab}$ & $18,00 \mathrm{abc}$ & $3,97 \mathrm{~cd}$ \\
\hline & Comum & $3,76 \mathrm{~cd}$ & $23,24 \mathrm{a}$ & $3,49 d$ \\
\hline \multirow[t]{4}{*}{ Trigo } & BRS 277 & $3,73 d$ & $13,80 \mathrm{c}$ & $5,22 \mathrm{abcd}$ \\
\hline & BRS Guatambu & 3,87bcd & $13,57 \mathrm{c}$ & $6,76 a$ \\
\hline & BRS Tarumã & 3,96bcd & $16,03 \mathrm{bc}$ & 6,33ab \\
\hline & BRS Umbu & 4,06bc & $19,75 \mathrm{ab}$ & $5,65 \mathrm{abc}$ \\
\hline CV (\%) & - & 2,66 & 11,51 & 13,68 \\
\hline
\end{tabular}

Médias seguidas por letras distintas na coluna diferem entre si pelo teste Tukey a 5\% de probabilidade.

* N-NH - Nitrogênio amoniacal em \% do nitrogênio total.

Tabela 4 - Percentuais de proteína bruta, nitrogênio insolúvel em detergente ácido (NIDA) e nitrogênio insolúvel em detergente neutro (NIDN)

\begin{tabular}{llccc}
\hline Espécie & Genótipo & Proteína bruta & NIDA* & NIDN* \\
\hline Triticale & BRS 148 & $8,45 \mathrm{a}$ & 14,25 & 9,74 \\
Cevada & BRS Marciana & $7,41 \mathrm{ab}$ & 15,01 & 9,13 \\
Centeio & BR 1 & $7,21 \mathrm{ab}$ & 18,05 & 14,36 \\
& BRS Serrano & $6,31 \mathrm{ab}$ & 17,19 & 19,87 \\
Aveia-branca & UPF 18 & $6,85 \mathrm{ab}$ & 17,30 & 13,88 \\
Aveia-preta & UPFA 21 - Moreninha & $5,97 \mathrm{~b}$ & 16,26 & 13,70 \\
& Agro-zebu & $6,20 \mathrm{ab}$ & 18,17 & 13,10 \\
Trigo & Comum & $7,25 \mathrm{ab}$ & 15,30 & 12,02 \\
& BRS 277 & $6,87 \mathrm{ab}$ & 16,81 & 12,94 \\
& BRS Guatambu & $7,96 \mathrm{ab}$ & 15,51 & 10,14 \\
CV (\%) & BRS Tarumã & $7,32 \mathrm{ab}$ & 15,60 & 10,82 \\
\hline
\end{tabular}

* Relativo ao nitrogênio total.

Médias seguidas por letras distintas na coluna diferem entre si pelo teste Tukey a 5\% de probabilidade. 
que a FDNcp foi, em média, 1,13 unidade percentual inferior à FDNc. Esta diferença numérica é oriunda da subtração da proteína insolúvel em detergente neutro (NIDN × 6,25) da FDNc, e a sua amplitude indica a importância desta correção para classificação das silagens quanto à qualidade. Os valores de FDAc e FDAcp também apresentaram comportamento similar, com diferença de 1,03 unidade percentual.

Os menores valores de FDNcp e de FDAcp foram obtidos para os trigo BRS Umbu, BRS Guatambu, BRS Tarumã, para a cevada BRS Marciana para o triticale BRS 148. Foi encontrada correlação negativa entre o percentual de grãos e os teores de FDNcp $(\mathrm{r}-0,35 ; \mathrm{P}=0,03)$ e de FDAcp $(r=-0,42 ; P=0,008)$. Esta associação confirma que a maior participação deste componente confere maior qualidade nutricional às silagens (Barrière et al., 1997). Ressalta-se que os teores de FDAcp observados, excetuando-se os genótipos de centeio e a aveia-preta UPFA21-Moreninha, são inferiores a 40\%, valor apontado por Nussio et al. (1998) como limitante ao consumo voluntário dos bovinos.
Lopes et al. (2008), avaliando silagens de triticale em diferentes idades de corte, observaram valores de 48,20 e 29,40\% de FDN e FDA, bem inferiores aos observados neste trabalho, enquanto Coan et al. (2001), avaliando silagens de aveia amarela do genótipo São Carlos e aveiapreta Comum, obtiveram valores médios de 60,5 e 37,25\% para estas variáveis, respectivamente, mais próximos aos deste trabalho.

Quanto ao teor de celulose (Tabela 6), o centeio BR 1 apresentou a maior concentração deste componente. O elevado valor de celulose observado para este genótipo está diretamente relacionado com a maior participação da fração FDAcp, uma vez que a celulose é importante componente desta fração. Esta afirmação é confirmada pela correlação encontrada entre estes dois componentes ( $\mathrm{r}=0,95 ; \mathrm{P}<0,0001)$. Verificou-se também correlação negativa da celulose com a participação de grãos $(r=0,42$; $\mathrm{P}=0,01)$, indicando que quanto maior a participação desse componente, menor o percentual de carboidratos estruturais na silagem. Com relação à hemicelulose, o maior valor foi observado para a aveia Agro Zebu. Os valores de

Tabela 5 - Fibra em detergente neutro e fibra em detergente ácido, corrigidas para cinzas (FDNc, FDAc) e para proteína (FDNcp, FDAcp) da silagem de cereais de inverno submetidos ao manejo de duplo propósito

\begin{tabular}{|c|c|c|c|c|c|}
\hline Espécie & Genótipo & FDNc & FDNcp & FDAc & FDAcp \\
\hline Triticale & BRS 148 & $62,65 \mathrm{abcd}$ & $61,45 \mathrm{abcd}$ & $37,55 b c d$ & 33,73bcd \\
\hline Cevada & BRS Marciana & $58,15 \mathrm{~cd}$ & $57,04 \mathrm{~cd}$ & $32,50 \mathrm{~d}$ & $31,83 d$ \\
\hline \multirow[t]{2}{*}{ Centeio } & BR 1 & $72,07 a b$ & $70,77 a$ & $45,93 a$ & $44,90 a$ \\
\hline & BRS Serrano & $69,84 \mathrm{ab}$ & $68,76 \mathrm{ab}$ & 41,31abc & $40,50 \mathrm{abc}$ \\
\hline Aveia-branca & UPF 18 & 68,38 abc & $67,26 a b c$ & 39,86abcd & 38,95abcd \\
\hline \multirow[t]{3}{*}{ Aveia-preta } & UPFA 21 - Moreninha & $72,63 a$ & $71,67 a$ & 44,13ab & $43,30 a b$ \\
\hline & Agro-zebu & $70,80 \mathrm{ab}$ & $69,67 a$ & 40,35abcd & 39,54abcd \\
\hline & Comum & $65,36 a b c d$ & $64,25 a b c d$ & 39,31abcd & $38,46 a b c d$ \\
\hline \multirow[t]{4}{*}{ Trigo } & BRS 277 & $68,40 \mathrm{abc}$ & 67,29abc & $38,82 \mathrm{abcd}$ & 37,96abcd \\
\hline & BRS Guatambu & 59,65bcd & 58,41 bcd & $34,18 \mathrm{~cd}$ & $33,73 \mathrm{~cd}$ \\
\hline & BRS Tarumã & $63,08 \mathrm{abcd}$ & 61,96abcd & $35,39 c d$ & $34,81 \mathrm{~cd}$ \\
\hline & BRS Umbu & $55,59 d$ & $54,53 d$ & $32,81 d$ & $32,06 \mathrm{~d}$ \\
\hline $\mathrm{CV}$ & - & 5,82 & 5,91 & 6,93 & 7,06 \\
\hline
\end{tabular}

Médias seguidas por letras distintas na coluna diferem entre si pelo teste Tukey a 5\% de probabilidade.

Tabela 6 - Percentuais de celulose, hemicelulose, lignina e sílica em silagens de cereais de inverno submetidas ao manejo de duplo propósito

\begin{tabular}{|c|c|c|c|c|c|}
\hline Espécie & Genótipo & Celulose & Hemicelulose & Lignina & Sílica \\
\hline Triticale & BRS 148 & 33,00abc & $25,10 \mathrm{bc}$ & 4,26bc & 1,50 \\
\hline Cevada & BRS Marciana & $30,10 \mathrm{bc}$ & $25,65 a b c$ & $3,21 \mathrm{c}$ & 1,36 \\
\hline \multirow{2}{*}{ Centeio } & BR 1 & $40,39 a$ & 26,13abc & 5,52ab & 1,14 \\
\hline & BRS Serrano & $35,97 a b c$ & $28,53 a b$ & $5,78 a$ & 1,31 \\
\hline Aveia-branca & UPF 18 & $34,42 a b c$ & $28,52 \mathrm{ab}$ & 5,45ab & 1,55 \\
\hline \multirow[t]{3}{*}{ Aveia-preta } & UPFA 21 - Moreninha & $37,78 a b$ & $28,50 \mathrm{ab}$ & $5,36 a b$ & 1,23 \\
\hline & Agro-zebu & $35,38 a b c$ & $30,45 a$ & 5,04ab & 1,44 \\
\hline & Comum & $34,18 \mathrm{abc}$ & $26,04 \mathrm{abc}$ & 4,42abc & 1,65 \\
\hline \multirow[t]{4}{*}{ Trigo } & BRS 277 & $33,55 a b c$ & $29,57 a b$ & 5,19ab & 1,44 \\
\hline & BRS Guatambu & $29,76 \mathrm{bc}$ & $25,47 a b c$ & 4,90ab & 1,69 \\
\hline & BRS Tarumã & $31,59 \mathrm{bc}$ & $27,49 a b c$ & 4,93ab & 1,60 \\
\hline & BRS Umbu & $29,00 c$ & $22,78 c$ & 4,17bc & 1,05 \\
\hline CV (\%) & - & 8,13 & 6,62 & 9,65 & 24,41 \\
\hline
\end{tabular}

Médias seguidas por letras distintas na coluna diferem entre si pelo teste Tukey a 5\% de probabilidade. 
celulose e hemicelulose encontrados no presente trabalho foram semelhantes aos observados por Coan et al. (2001), trabalhando com silagem de aveia pré-emurchecida.

Os teores mais elevados de lignina foram observados para o centeio BRS Serrano, sendo semelhantes aos relatados por Hernández et al. (2002), de 5,35 e 5,29\% da MS, respectivamente para silagens de milho sem e com inoculante. A lignina está associada à FDAcp, condição essa confirmada no presente trabalho $(\mathrm{R}=0,74$; $\mathrm{P}<0,0001)$ e diretamente relacionada com a digestibilidade da forragem, uma vez que é a fração da fibra totalmente indigestível. O menor teor de lignina foi observado para a cevada BRS Marciana. Coan et al. (2001), trabalhando com silagem pré-emurchecida, observaram teores de lignina de 5,2\% em genótipos de triticale e aveia, semelhantes aos observados no presente trabalho. Para os teores de sílica, os resultados foram similares entre os genótipos testados.

\section{Conclusões}

Todos os genótipos testados apresentam condições para ser ensilados e produzem silagens com características fermentativas desejáveis. O triticale BRS 148 e o centeio BR 1 são os genótipos mais precoces para produção de silagem. O centeio BR 1 e a aveia UPF 18 apresentam o maior rendimento de massa seca de pré-ensilagem. O trigo BRS Umbu tem maior participação de grãos e de lâminas foliares na massa total, o que proporciona silagem com maior qualidade nutricional.

\section{Referências}

BARRIÈRE, Y.; ARGILLIER, O.; MICHALET-DOREAU, B. et al. Relevant traits, genetic variation and breeding strategies in early silage maize. Agronomie, v.17, n.5, p.395-411, 1997.

CHANEY, A.L.; MARBACH, E.P. Modified reagents for determination of urea and ammonia. Clinical Chemistry, v.8, n.2, p.130-162, 1962.

COAN, R.M.; FREITAS, D.; REIS, R.A. et al. Composição bromatológica das silagens de forrageiras de inverno submetidas ou não ao emurchecimento e ao uso de aditivos. ARS Veterinária, v.17, n.1, p.58-63, 2001.

COMISSÃO DE QUÍMICA E FERTILIDADE DO SOLO. Manual de adubação e calagem para os estados do Rio Grande do Sul e de Santa Catarina. 10.ed. Porto Alegre: SBCS-NRS, 2004. 400p.

DUMONT, L.J.C.; LANUZA, A.F.; ELIZALDE, V.H.F. Use of ensiled oats harvest at two growth stages and effects of protein supplementation in dairy cows. Agricultura Técnica, v.49, n.31, p.5-13, 1989.

EMPRESA BRASILEIRA DE PESQUISA E AGROPECUÁRIA EMBRAPA. Sistema brasileiro de classificação de solos. Brasília: Centro Nacional de Pesquisa de Solos; Rio de Janeiro: Embrapa, 1999. 412p.

EVANGELISTA, A.R.; ABREU, J.G.; AMARAL, P.N.C. et al. Produção de silagem de capim-marandu (Brachiaria brizantha Stapf cv. Marandu) com e sem emurchecimento. Ciência e Agrotecnologia, v.28, n.2, p. 443-44, 2004.
FERREIRA, J.J. Estágio de maturação ideal para ensilagem do milho e do sorgo. In: CRUZ, J.C.; PEREIRA FILHO, I.A.; RODRIGUES, J.A.S. et al. (Eds). Produção e utilização de silagem de milho e sorgo. Sete Lagoas: Embrapa Milho e Sorgo, 2001. p.405-428.

FISHER, D.S.; BURNS, J.C. Quality analysis of summer-annual forages. II. Effects of forage carbohydrate constituents on silage fermentation. Agronomy Journal, v.79, n.2, p.242-248, 1987.

FONTANELI, Ren.S.; FONTANELI, Rob.S.; SANTOS, H.P. et al. Rendimento e valor nutritivo de cereais de inverno de duplo propósito: forragem verde e silagem ou grãos. Revista Brasileira de Zootecnia, v.38, n.11, p.2116-2120, 2009.

FLOSS, L.F.; BOIN, C.; PALHANO, A.L. et al. Efeito do estádio de maturação sobre o rendimento e valor nutritivo da aveiabranca no momento da ensilagem. Boletim da Industria Animal, v.60, n.2, p.117-126, 2003.

HERNÁNDEZ, F.I.L.; VALADARES FILHO, S.C.; PAULINO, M.F. et al. Avaliação da composição de vários alimentos e determinação da cinética ruminal da proteína, utilizando o método de produção de gás e amônia in vitro. Revista Brasileira de Zootecnia, v.31, n.1, p.243-255, 2002.

KUNG JUNIOR, L.; STOKES, M.R.; LIN, C.J. Silage additives. In: BUXTON, D.R.; MUCK, R.E.; HARRISON, J.H. (Eds.) Silage science and technology. Madison: American Society of Agronomy; Crop Science Society of America; Soil Science Society of America, 2003. p.251-304.

LOPES, F.C.F.; SILVA E OLIVEIRA, J.; LANES, E.C.M. et al. Valor nutricional do triticale ( $X$ Triticosecale Wittmack) para uso como silagem na Zona da Mata de Minas Gerais. Arquivo Brasileiro de Medicina Veterinária e Zootecnia, v.60, n.6, p.1484-1492, 2008.

MAYOMBO, A.P.; DUFRASNE, I.; HORNICK, J.L et al. Influencie du stade de maturité de la plante de may recolteé pour ensilage sur la composition, la digestibilité aparente, les caractéristiques de fermentation dans le rume et les performances zootechniques chez le taurillon à I'engraissement. Animal Zootech, v.46, n.1, p.43-55, 1997.

McDONALD, P. The biochemistry of silage. New York: John Wiley \& Sons, 1981. p.226

MOISIO, T.; HEIKONEN, M. Lactic acid fermentation in silage preserved with formic acid. Animal Feed Science and Technology, v.47, n.1-2, p.107-124, 1994.

Moreno, J.A. Clima do Rio Grande do Sul. Porto Alegre: Secretaria da Agricultura, 1961. 41p.

NOLLER, C.H.; STILLONS, M.C.; MARTZ, F.A. et al. Digestion studies with oat silages using a new fecal collection technique. Journal of Animal Science, v.18, n.2, p.671-675, 1954.

NOVAES, L.P.; LOPES, F.C.F.; CARNEIRO, J.C. Silagens: pontos críticos e oportunidades. Brasília: Embrapa Cerrados; Juiz de Fora: Embrapa Gado de Leite, 2004. 10p.

NUSSIO, L.G.; MANZANO, R.P.; PEDREIRA, C.G.S. Valor alimentício em plantas do gênero Cynodon. In: PEIXOTO, A.M.; MOURA, J. C.; FARIA, V.P. (Eds.) Manejo de pastagens de tifton, coastcross e estrela. Piracicaba: FEALQ, 1998. p.203-242.

OLIVEIRA, L.B. Produção e valor nutritivo de diferentes forrageiras e as suas respectivas silagens. 2008. 46f. Dissertação (Mestrado em Agronomia) - Universidade Estadual do Sudoeste da Bahia, Vitória da Conquista.

PEREIRA, J.R.A.; REIS. R.A. Produção de silagem pré-secada com forrageiras temperadas e tropicais. In: SIMPÓSIO SOBRE PRODUÇÃO E UTILIZAÇÃO DE FORRAGENS CONSERVADAS, 2011, Maringá. Anais... Maringá: Universidade Estadual de Maringá, 2001. p.64-86.

PLAYNE, M.J.; McDONALD, P. The buffering constituints of herbage and of silage. Journal Science Food and Agriculture, v.17, n.2, p.264-268, 1966.

PINTO, A.P.; MIZUBUTI, I.Y.; RIBEIRO, E.L.A. Avaliação da silagem de bagaço de laranja e silagem de milho em diferentes 
períodos de armazenamento. Acta Scientiarum Animal Sciences, v.29, n.4, p.371-377, 2007.

PRIMAVESI, A. C.; PRIMAVESI, O.; CHINELlATO, A. et al. Indicadores de determinação de cortes de cultivares de aveia forrageira. Scientia Agricola, v.58, n.1, p.79-89, 2001.

RANJIT, N.K.; KUNG JR., L. The effect of Lactobacillus buchneri, Lactobacillus plantarum, or a chemical preservative on the fermentation and aerobic stability of corn silage. Journal of Dairy Science, v.83, n.3, p.526-535, 2000.

SCHEFFER-BASSO, S.M.; DÜRR, J.W.; FONTANELI, R.S. Valor nutritivo de forragens: concentrados, pastagens e silagens.
Passo Fundo: Universidade de Passo Fundo - Centro de Pesquisa em Alimentação, 2003. 31p.

SCHEFFER-BASSO, S.M.; AGRANIONIK, H.; FONTANELI, R.S Acúmulo de biomassa e composição bromatológica de milhetos das cultivares comum e africano. Revista Brasileira de Agrociência, v.10, n.4, p.483-486, 2004.

SILVA, D.J.; QUEIROZ, A.C. Análise de alimentos: métodos químicos e biológicos. 3.ed. Viçosa, MG: UFV, 2002. 235p.

VAN SOEST, P.J. Nutritional ecology of the ruminant. Ithaca: Cornell University, 1994. 476p. 